\title{
Positivity and negativity in interparental conflict
}

\author{
Zemp, Martina ; Bodenmann, Guy ; Backes, Sabine ; Sutter-Stickel, Dorothee ; Bradbury, Thomas N
}

\begin{abstract}
Although children are known to be highly sensitive to interparental conflict, important questions remain regarding which specific combinations of positive and negative behaviors as well as verbal and nonverbal expressions are most predictive of children's perceptions. In this pilot study, we examined observational data on interparental conflict as predictors of children's reports of perceived threat and insecurity in 43 families. Fathers' nonverbal negativity was strongly linked to children's perceived threat and insecure family representations, but both parents' nonverbal and mothers' verbal positivity buffered its impact on children. Our findings support previous research findings that parents' negativity may have less adverse effects on children when it takes place in a positive family climate.
\end{abstract}

DOI: https://doi.org/10.1024/1421-0185/a000182

Posted at the Zurich Open Repository and Archive, University of Zurich

ZORA URL: https://doi.org/10.5167/uzh-132039

Journal Article

Accepted Version

Originally published at:

Zemp, Martina; Bodenmann, Guy; Backes, Sabine; Sutter-Stickel, Dorothee; Bradbury, Thomas N (2016). Positivity and negativity in interparental conflict. Swiss Journal of Psychology, 75(4):167-173.

DOI: https://doi.org/10.1024/1421-0185/a000182 
RUNNING HEAD: IMPACT OF PARENTS' POSITIVITY AND NEGATIVITY

Positivity and negativity in interparental conflict:

Implications for children

\author{
Martina Zemp ${ }^{\mathrm{a}}$, Guy Bodenmann ${ }^{\mathrm{b}}$, Sabine Backes $^{\mathrm{b}}$, Dorothee Sutter-Stickel ${ }^{\mathrm{b}}$, \\ \& Thomas N. Bradbury ${ }^{\mathrm{c}}$
}

Accepted for publication in the Swiss Journal of Psychology.

${ }^{\mathrm{a} C}$ Corresponding author: Martina Zemp, University of Zurich, Department of Psychology, Binzmuehlestrasse 14/23, 8050 Zurich, Switzerland; Email:

martina.zemp@psychologie.uzh.ch, Phone number: +41 446357388.

${ }^{\mathrm{b}}$ University of Zurich, Department of Psychology

${ }^{c}$ University of California Los Angeles (UCLA), Department of Psychology 


\begin{abstract}
Although children are known to be highly sensitive to interparental conflict, important questions remain regarding which specific combinations of positive and negative behaviors, and verbal and nonverbal expressions, are most predictive of these perceptions. In this pilot study, we examined observational data on interparental conflict as predictors of child reports of threat and insecurity in 43 families. Fathers' nonverbal negativity was strongly linked to children's perceived threat and insecure family representations, but both parents' nonverbal and mothers' verbal positivity buffered its impact on children. Findings support past research that parents' negativity may have less adverse effects on children when it takes place in a positive family climate.
\end{abstract}

Keywords: intimate relationship, couple, parents, communication quality, interaction 
Interparental conflict is well established as a major predictor of child maladjustment (Cummings \& Davies, 2010). Two leading models propose key variables explaining this association. First, the cognitive-contextual model (Grych \& Fincham, 1990) posits that children who perceive high levels of threat when faced with interparental conflict are likely to be particularly distressed. Second, emotional security theory (Davies \& Cummings, 1994) holds that maintaining felt security is a primary goal for children in the family setting. According to this theory, children from high-conflict homes are expected to develop insecure family representations, marked by low confidence in parents' abilities to manage difficulties for the purpose of preserving family stability. Both dimensions, perceived threat and insecure family representations, were empirically supported in a number of longitudinal tests as explanatory mechanisms linking interparental conflict and children's long-term adjustment (e.g., Cummings, George, McCoy, \& Davies, 2012; Grych, Harold, \& Miles, 2003). The present study builds directly on these two models, using observational data on interparental conflict to specify the dimensions that predict children's perceptions of threat and insecurity in this context.

Previous research has reported that it is not whether couples argue but how they do that is most pertinent to the well-being of children. For instance, there is growing evidence for the existence of positive conflict tactics from the child's perspective. Goeke-Morey, Cummings, Harold, and Shelton (2003) classified interparental conflict behaviors by means of children's responses to vignettes of adult interactions. They found a continuum from most destructive to most constructive conflicts, with physical aggression at one extreme and affection and support at the other. A study based on parents' diary reports confirmed these categorizations of interparental conflict (Cummings, Goeke-Morey, \& Papp, 2003). Notably, children are also distressed by nonverbal anger in interparental conflicts (Cummings et al., 2003; Goeke-Morey et al., 2003). In the study by Sturge-Apple, Davies, and Cummings (2006), interparental withdrawal (i.e., forms of detachment and avoidance during interactions) 
emerged as a more powerful predictor of children's maladjustment than parents' overt hostility. In line with the notion that children are exceptionally sensitive to interparental tensions, children distinguish "mixed message resolution" (inconsistent in content and emotion, e.g., an angry apology) from consistently positive conflict endings when responding to analogue unresolved conflicts (Shifflett-Simpson \& Cummings, 1996). They are also sensitive to adults' emotional tone in their tendency to display negative reactions when faced with interparental conflict (Cummings, Goeke-Morey, Papp, \& Dukewich, 2002). In sum, these prior findings showed that (1) observational data of interparental conflict are a particularly reliable measure in the field and (2) the impact of interparental conflict on children is probably best understood by taking the child's perceptions into consideration.

Growing literature suggests that the consequences of interparental conflict for children might depend on the combination of positive and negative interactions than on the absolute frequency of either. Children whose parents describe their family climate as high in negative affect and low in positive affect are most likely to blame themselves for interparental conflict; thus it is the combination of negativity and positivity that appears to best explain variation in self-blaming appraisals (Fosco \& Grych, 2007). Similarly, Zemp, Merrilees, and Bodenmann (2014) investigated child outcomes as a function of the ratio of their parents' reports of positivity to negativity and found that higher ratios of positivity-to-negativity in parents' interactions are significantly associated with children's well-being. The detrimental impacts of interparental negativity were buffered by their positive everyday interactions.

In sum, although prior studies have begun to specify the characteristics of interparental conflict that most likely affect children, to our knowledge studies have not yet employed observational data on couple interaction to investigate how two key dimensions of couple interaction, i.e., positivity versus negativity (the affective quality of behavior), and verbal versus nonverbal behaviors (the mode of communication) combine to predict child perceptions of threat and insecure family representations. The present study aims to fill this 
gap by testing three hypotheses: First, we assume that higher levels of parents' negativity, whether verbal or nonverbal, will predict higher levels of perceived threat and insecurity in children (H1). Second, we predict that higher levels of parents' positivity, whether verbal or nonverbal, will predict lower levels of perceived threat and insecurity, over and above parents' negativity $(\mathrm{H} 2)$. Third, we hypothesize that the adverse effects of negative behavior on child perceptions will be moderated by parents' positivity (H3). We test these predictions with a sample of children aged $9-13$ and we control for child age and gender in all analyses given the importance of these variables in this context. However, we do not propose any firm hypotheses concerning gender or age effects given that prior research has been inconsistent in this regard (Cummings \& Davies, 2010; Davies \& Lindsay, 2001).

\section{Method}

\section{Participants}

A total of $N=43$ ( 25 boys, 18 girls) children and their parents participated in this study which was part of a larger research project on the impact of stress on intimate relationships. Participants were recruited by means of advertisements in print media, online advertising, and by radio. To be included in the larger project, couples had to be in their current relationship for at least one year and spouses had to be fluent in German. For the current study, the additional inclusion criterion was that couples had at least one child aged 9 - 13 living in the same household. If participants had more than one child in the respective age range then only the youngest eligible child ("target child") was included in the final sample.

Mothers and fathers averaged 43.6 years $(S D=3.52$, range $=33-49$ years $)$ and 46.2 years $(S D=4.13$, range $=32-54$ years $)$, respectively. Most spouses were Swiss $(88 \%$ of females, $97 \%$ of males), and most couples (94\%) were married. Relationship duration ranged from 4 to 32 years $(M=18.9$ years, $S D=7.15)$. The mean number of children per family was $2.6(S D=.98$, range $=1-4)$. Target children averaged 10.6 years of age $(S D=1.46$, range $=$ 
9 - 13). All target children lived with both their biological parents except for 5 children who had lived with their biological mother and their stepfather since toddler age.

\section{Procedure}

Assessment of parents and children took place in a university laboratory. After the introduction by the examiner, both partners and their child were asked to sign the consent form. Subsequently, children completed a set of questionnaires guided by an examiner. The parents participated in an interaction task in a separate room. They independently rated a list of 13 potential conflict topics for couples (e.g., child-rearing, money etc.) in how problematic they were in their relationship on a 4-point Likert scale. The examiner then identified the most problematic topic for both partners. The couples discussed the selected topic for 8 min while they were alone in the laboratory room. Videotaped records of the session were obtained for later coding of conflict behaviors. At the end of the session, couples received 100 Swiss Francs (approximately \$105) and the children received a little present.

\section{Measures}

Parents' interactions. Observational scales for parents' positivity and negativity were developed by Bodenmann (2011) in an adapted version of the SPAFF coding system (Gottman \& Krokoff, 1989). The coding system consisted of four main categories: verbal positivity, verbal negativity, nonverbal positivity, and nonverbal negativity. The categories were separately coded for mothers and fathers as it is well established in the field to account for the gender-differentiated communication patterns in parents (Cummings, Cummings, Goeke-Morey, Du Rocher Schudlich, \& Cummings, 2010). Verbal positivity consisted of four subcategories: interest, validation, affect/caring, and constructive communication. Verbal negativity consisted of seven subcategories: criticism, defensiveness, domineering, stonewalling, formal negative interaction, contempt, and belligerence. Total scores of mothers' and fathers' verbal positivity and verbal negativity were achieved by summarizing the responses across the subcategories over the $8 \mathrm{~min}$ of discussion. The categories of 
nonverbal positivity and nonverbal negativity did not derive from specific predefined subcategories. Examples of nonverbal positivity include nodding, caring, smiling, laughing, kissing, hugging, or stroking. Examples of nonverbal negativity include refusal, rejection, withdrawal, hostile gestures or facial expressions, head-shaking, or sarcastic laughter. Total scores of mothers' and fathers' nonverbal positivity and nonverbal negativity were achieved by summarizing all responses over the 8 min of discussion.

Videotaped interactions were rated by two raters simultaneously, one focusing on the father, the other focusing on the mother. The raters coded verbal and nonverbal interactions in two separate passes. Interactions were divided into 48 10-sec sequences to allow for the possibility that multiple categories could occur during the 8-min interaction. Responses were rated every 10 seconds for the occurrence of the categories or subcategories, respectively $(0=$ did not occur; $1=$ did occur ). This coding system has been used in previous research, thus supporting its validity (e.g., Kuster et al., 2015). Research assistants were trained for a minimum of 60 hours to master the coding system. Coding was practiced with videotaped couples that were not participants in the study. At the end of the training period, all rater teams had achieved a high interrater-reliability (Cohen's kappa of at least .90).

Children's perceived threat. One subscale of the German version of the Children's Perception of Interparental Conflict Scale (CPIC; Schwarz \& Siffert, 2010, originally developed by Grych, Seid, \& Fincham, 1992) was used to assess children's perceptions of threat in interparental conflict. The children rated the six items of the subscale Perceived Threat (e.g., I get scared when my parents argue) on a 5-point Likert scale ranging from 1 (never) to 5 (very often). Cronbach's alpha in the present study was $\alpha=.90$.

Children's insecure family representations. One subscale of the Security in the Interparental Subsystem Scale (SISS; Davies, Forman, Rasi, \& Stevens, 2002) was translated to German to assess children's emotional insecurity. The translated questionnaire was tested in an independent sample of children of the same age and revealed good psychometric 
properties and a factor structure largely consistent with the American original (Zemp \& Bodenmann, 2014). The children completed the four items of the subscale Insecure Family Representations (e.g., When my parents have an argument I wonder if they will separate or divorce) on a 4-point Likert scale ranging from 1 (not at all true) to 5 (very true). Internal consistency was $\alpha=.73$ in the current study.

\section{Data analysis}

Hierarchical multiple regression analyses (Cohen, Cohen, West, \& Aiken, 2003) were conducted to test the study hypotheses. In all analyses we controlled for children's gender and age, entering them in the first step of the regression. For H1 and H2, mothers' and fathers' verbal and nonverbal negativity followed in the second step, and their verbal and nonverbal positivity were entered in the last step. For H3, fathers' nonverbal negativity and the four moderators (namely mothers' verbal positivity, mothers' nonverbal positivity, fathers' verbal positivity, and fathers' nonverbal positivity) formed the second step in four separate regression analyses. In each regression analysis the two-way interaction between fathers' nonverbal negativity and the four forms of positivity was entered in the third step. All numerical predictors were mean centered in order to simplify the interpretation of significant interactions and to eliminate multicollinearity.

\section{Results}

As shown in Table 1, all indicators of mothers' and fathers' verbal and nonverbal positivity and negativity were highly intercorrelated, as were measures of children's perceptions (i.e., children's perceived threat and children's insecure family representations). Unexpectedly, there was a significant link between mothers' verbal positivity and their nonverbal negativity.

Listed in Table 2 are the effects of parents' verbal and nonverbal positivity and negativity on children's perceived threat and insecure family representations. Children's insecure family representations were negatively associated with children's age with older 
children reporting lower levels of insecurity $(\beta=-.28, p=.016)$. Nonverbal negativity of fathers was significantly linked with higher levels of perceived threat $(\beta=.47, p=.016)$ and higher insecurity $(\beta=.57, p=.002)$. Overall, $23 \%$ of the variance in children's perceived threat and $35 \%$ of the variance in children's insecure family representations could be explained by mothers' and fathers' verbal and nonverbal negativity. However, mothers' and fathers' positivity (either verbal or nonverbal) was not significantly linked to children's perceived threat or insecure family representations and could not explain additional variance above parents' negativity.

According to the findings depicted in Table 2, when all indicators of parents' verbal and nonverbal negativity and positivity measured in this study are considered in the same analysis, only the fathers' nonverbal negativity had a significant impact on children's perceived threat and insecure family representations. We thus decided to use only this predictor for the moderation hypothesis (H3). That is, we tested whether the effects of fathers' nonverbal negativity on children's perception of threat and insecure family representations were buffered by the four forms of positivity (i.e., mothers' verbal positivity, mothers' nonverbal positivity, fathers' verbal positivity, fathers' nonverbal positivity) in a series of regression analyses. When predicting children's perceived threat, the interactions of fathers' nonverbal negativity with any form of positivity were not significant. Thus, parents' positivity didn't moderate the link between fathers' nonverbal negativity and children's perceived threat. However, mothers' verbal positivity was found to be a moderator of the impact of fathers' nonverbal negativity on children's insecure family representations $\left(\beta=-.29, \Delta R^{2}=\right.$ $.06, p=.021)$. Following Cohen et al. (2003), the significant two-way interaction was interpreted by plotting the simple regression lines for high and low values of the moderator (i.e., $1 S D$ above and below the mean; see Figure 1) and the simple slopes were then examined whether they were significantly different from zero. The simple slope test revealed that fathers' negativity was significantly linked with children's insecurity only under 
conditions of low mothers' verbal positivity $(b=.16, p<.001)$, but not in case of high mothers' verbal positivity $(b=.04, p=.262)$. Similarly, mothers' nonverbal positivity moderated the link between fathers' nonverbal negativity and children's insecure family representations $\left(\beta=-.36, \Delta R^{2}=.09, p=.007\right.$; interaction plot is not presented). Tests of simple slopes showed that fathers' nonverbal negativity was significantly associated with children's insecurity when mothers' nonverbal positivity was low $(b=.16, p<.001)$, but not when it was high $(b=.01, p=.875)$. Last, fathers' nonverbal positivity mitigated the impact of fathers' nonverbal negativity $\left(\beta=-.52, \Delta R^{2}=.12, p=.003\right.$; interaction plot is not presented). When fathers' nonverbal positivity was low, fathers' nonverbal negativity was significantly related to children's insecurity $(b=.22, p<.001)$, but it was negatively linked to children's insecurity when fathers' nonverbal positivity was high $(b=-.14, p=.004)$.

\section{Discussion}

Interparental conflict is a serious form of stress in the context of children's development. Replicating abundant literature, our results indicate that children are highly sensitive recipients for their parents' interactions, including their nonverbal signs of conflict. However, verbal and nonverbal positivity between parents were weaker predictors of outcomes in comparison to negativity. Among the forms of negativity, fathers' nonverbal negativity had the strongest association with perceived threat and insecurity in children. This finding matches prior research showing that children are highly responsive to nonverbal signs of interparental negativity (e.g., Cummings et al., 2003) and evidence exists that this may be especially true when expressed by fathers. For instance, Katz and Gottman (1993) examined different conflict communication patterns in parents as predictors of child adjustment. They found that mutual (both mothers' and fathers') hostility longitudinally predicted children's externalizing behaviors, whereas the often observed wife-demand - husband-angry/withdrawn pattern (i.e., high levels of withdrawal, stonewalling, and nonresponsiveness in fathers towards mothers) predicted children's internalizing problems. Along similar lines, Buehler et 
al. (1998) found that parents' use of an overt conflict style was uniquely associated with youth externalizing symptoms, while covert conflict was uniquely linked with their internalizing problems. It appears that children embedded in a family setting where overt conflicts are accompanied or replaced by nonverbal negativity may learn that unspoken tension is a viable way of coping with stressful events and may thus be prone to internalize their feelings of distress. The two main outcomes of the present study, i.e., children's perceived threat and insecure family representations, can also be considered as a form of internalizing problems and the findings seem thus consistent with previous research.

We found a negative association between children's age and children's insecure family representations. An extensive literature suggests that children of all ages (from toddlerhood through adolescence) show some type of negative reaction to interparental conflict but children of different ages show different types of reactions (Heinrichs, Cronrath, Degen, \& Snyder, 2010). In accordance with our finding it has been shown that children, as they age, become better able to cope with interparental conflict and develop greater capabilities to regulate their exposure to it (Cummings, Ballard, El-Sheikh, \& Lake, 1991). However, other research is at odds with our results: Cummings, Schermerhorn, Davies, Goeke-Morey, and Cummings (2006) found that interparental conflict was a stronger predictor of children's emotional security for older children. Further explication of age effects may shed some light on these inconsistencies and may clarify whether our findings are generalizable to other age groups.

Although mothers' and fathers' positivity (either verbal or nonverbal) was not directly related to children's perceived threat or children's insecure family representations and did not explain a significant proportion of variance beyond negativity, it was nonetheless an important buffer against negativity. That is, both parents' nonverbal positivity and mothers' verbal positivity mitigated the impact of fathers' nonverbal negativity on children's insecure family representations, but not on children's perception of threat in conflicts. In the study by 
Davies, Martin, and Cicchetti (2012) interparental positivity also failed to moderate links between children's exposure to destructive interparental conflict and their perceived threat. These authors discuss the possibility that interparental threat cues (i.e., negativity in any form) may be superior in shaping children's distress reactions compared to constructive interactions because these cues elicit efforts by the child to shelter him- or herself from social threat. The child's processing of threatening and negative expressions may be rapid and automatic, in a way that it is relatively impervious to parental positivity. Compared to children's perception of threat in interparental conflict, the development of insecure family representations reflects their more global evaluations of the family climate and is therefore likely affected by parents' negativity and positivity. Our result that parents' positivity offset the link between fathers' nonverbal negativity and children's insecure family representations aligns with Davies, Harold, and colleagues' (2002) finding that interparental conflict was a weaker predictor of child's emotional insecurity in families in which parents discuss their feelings in a constructive way.

Hence, interparental negativity may have less adverse effects on children when parents succeed in compensating with instances of positive and supportive behavior, a finding that has important implications for clinical practice. Parents do not have to repress their disagreements, but they should endeavor to outweigh them by positive interactions. Children's wellbeing can be assumed to depend largely on marital functioning beyond interparental conflict, with parents' positive reciprocity as promising buffers. That is, a focus on resources in prevention or treatment approaches seems timely and more promising than simply reducing negativity. There is growing evidence that treatments aimed at reducing interparental negativity and fostering positivity are promising in their inherent potential to enhance children's well-being (e.g., Cowan, Cowan, \& Barry, 2011; Cummings, Faircloth, Mitchell, Cummings, \& Schermerhorn, 2008).

Several limitations of this study merit discussion. First, as our sample size is 
relatively small, caution is warranted in interpreting and generalizing findings until they are replicated in larger samples. Longitudinal studies are also needed to determine the potential long-term consequences of the observed interactions. Second, by virtue of ethical concerns, children reported on their general perception of interparental conflict (perceived threat and emotional insecurity) by means of questionnaires, but they did not estimate the actual conflict occurring in the laboratory. However, findings from couple research indicate that spousal disagreements in the lab are a viable proxy for the quality of the couples' interactions at home (Gottman, 1979; see also Bradbury, Fincham, \& Beach, 2000). Third, the conflict topics the couples discussed were selected based on a rating list of possibly stressful topics. As only 9 couples (21\%) chose children to talk about in the discussion it was not possible to control whether the effects were different depending on the chosen topic (i.e., child-related versus other conflict). This is a limitation given that coparental arguments (child- or parenting-related conflict) are the types of conflicts that are most distressing to children (Grych \& Fincham, 1990). Fourth, we used self-reported data of children and observational data of parents. This multimethod approach is a strength of the study, although, by the same token, an important source of information is missing: the parents' perceptions. Fifth, we focused on the Perceived Threat subscale from the CPIC and did not examine children's self-blaming attributions as outcome measures. Given previous findings reported by Fosco and Grych (2007) our hypotheses merit testing for children's self-blame in a future investigation. Sixth, parent-child interactions were not examined in the present study and we thus cannot establish from our data whether the reported effects were mediated by parenting variables.

Notwithstanding these limitations, this study extends earlier research on children's sensitivity to interactions between parents. The findings revealed that multiple aspects of dyadic functioning in parents combine to explain variance in child development. Interparental 
conflict is not an isolated occurrence in everyday family life, but must be weighed against positive interactions in the parents' relationship. The effect of couple conflicts and parents' negative interactions on children may be mitigated by parents' positivity and, hence, conflicts may be less severe to children's well-being when they are buffered by positivity. 


\section{References}

Bodenmann, G. (2011). Kodiersystem zur Erfassung der dyadischen Kommunikation bei Paaren. [Coding system to assess the dyadic communication in couples].

Unveröffentlichtes Manual [Unpublished manual]. University of Zurich, Switzerland.

Bradbury, T. N., Fincham, F. D., \& Beach, S. R. H. (2000). Research on the nature and determinants of marital satisfaction: A decade in review. Journal of Marriage \& Family, 62(4), 964-980.

Buehler, C., Krishnakumar, A., Stone, G., Anthony, C., Pemberton, S., Gerard, J., \& Barber, B. K. (1998). Interparental conflict styles and youth problem behaviors: A two-sample replication study. Journal of Marriage and the Family, 60(1), 119-132.

Cohen, J., Cohen, P., West, S. G., \& Aiken, L. S. (2003). Applied multiple regression/correlation analysis for the behavioral sciences. Mahwah: Erlbaum Associates.

Cowan, C. P., Cowan, P. A., \& Barry, J. (2011). Couples' groups for parents of preschoolers: Ten-year outcomes of a randomized trial. Journal of Family Psychology, 25(2), 240250. http://doi.org/10.1037/a0023003

Cummings, E. M., Ballard, M., El-Sheikh, M., \& Lake, M. (1991). Resolution on children's responses to interadult anger. Developmental Psychology, 27, 462-470. http://doi.org/10.1037/0012-1649.27.3.462

Cummings, E. M., Cummings, J. S., Goeke-Morey, M. C., Du Rocher Schudlich, T. D., \& Cummings, C. M. (2010). Conflict in the interparental system (CIS): Observational coding. In E. M. Cummings \& P. T. Davies (Eds.), Marital conflict and children. (pp. 229-233). New York: The Guilford Press.

Cummings, E. M., \& Davies, P. T. (2010). Marital conflict and children: An emotional security perspective. New York: The Guilford Press.

Cummings, E. M., Faircloth, W. B., Mitchell, P. M., Cummings, J. S., \& Schermerhorn, A. C. 
(2008). Evaluating a brief prevention program for improving marital conflict in community families. Journal of Family Psychology, 22(2), 193-202. http://doi.org/10.1037/0893-3200.22.2.193

Cummings, E. M., George, M. R., McCoy, K. P., \& Davies, P. T. (2012). Interparental conflict in kindergarten and adolescent adjustment: Prospective investigation of emotional security as an explanatory mechanism. Child Development, 83(5), 17031715. http://doi.org/10.1111/j.1467-8624.2012.01807.x

Cummings, E. M., Goeke-Morey, M. C., \& Papp, L. M. (2003). Children’s responses to everyday marital conflict tactics in the home. Child Development, 74(6), 1918-1929.

Cummings, E. M., Goeke-Morey, M. C., Papp, L. M., \& Dukewich, T. L. (2002). Children’s responses to mothers' and fathers' emotionality and tactics in marital conflict in the home. Journal of Family Psychology, 16(4), 478-92.

Cummings, E. M., Schermerhorn, A. C., Davies, P. T., Goeke-Morey, M. C., \& Cummings, J. S. (2006). Interparental discord and child adjustment: Prospective investigations of emotional security as an explanatory mechanism. Child Development, 77(1), 132-152. http://doi.org/10.1111/j.1467-8624.2006.00861.x

Davies, P. T., \& Cummings, E. M. (1994). Marital conflict and child adjustment: An emotional security hypothesis. Psychological Bulletin, 116(3), 387-411. http://doi.org/10.1037/0033-2909.116.3.387

Davies, P. T., Forman, E. M., Rasi, J. A., \& Stevens, K. I. (2002). Assessing children's emotional security in the interparental relationship: The Security in the Interparental Subsystem Scale. Child Development, 73(2), 544-562.

Davies, P. T., Harold, G. T., Goeke-Morey, M. C., Cummings, E. M., Shelton, K., Rasi, J. A., \& Jenkins, J. M. (2002). Child emotional security and interparental conflict. Monographs of the Society for Research in Child Development, 67(3), 1-115. http://doi.org/10.2307/3181513 
Davies, P. T., \& Lindsay, L. L. (2001). Does gender moderate the effects of marital conflict on children? In J. H. Grych \& F. D. Fincham (Eds.), Interparental conflict and child development: Theory, research, and applications (pp. 64-97). New York: Cambridge University Press.

Davies, P. T., Martin, M. J., \& Cicchetti, D. (2012). Delineating the sequelae of destructive and constructive interparental conflict for children within an evolutionary framework. Developmental Psychology, 48(4), 939-955. http://doi.org/10.1037/a0025899

Fosco, G. M., \& Grych, J. H. (2007). Emotional expression in the family as a context for children's appraisals of interparental conflict. Journal of Family Psychology, 21(2), 248-258. http://doi.org/10.1037/0893-3200.21.2.248

Goeke-Morey, M. C., Cummings, E. M., Harold, G. T., \& Shelton, K. H. (2003). Categories and continua of destructive and constructive marital conflict tactics from the perspective of U.S. and Welsh children. Journal of Family Psychology, 17(3), 327338. http://doi.org/10.1037/0893-3200.17.3.327

Gottman, J. M. (1979). Marital interaction. New York: Academic Press.

Gottman, J. M., \& Krokoff, L. J. (1989). Marital interaction and satisfaction: A longitudinal view. Journal of Consulting and Clinical Psychology, 57(1), 47-52. http://doi.org/10.1037/0022-006X.57.1.47

Grych, J. H., \& Fincham, F. D. (1990). Marital conflict and children's adjustment: A cognitive-contextual framework. Psychological Bulletin, 108(2), 267-290.

Grych, J. H., Harold, G. T., \& Miles, C. J. (2003). A prospective investigation of appraisals as mediators of the link between interparental conflict and child adjustment. Child Development, 74(4), 1176-1193.

Grych, J. H., Seid, M., \& Fincham, F. D. (1992). Assessing marital conflict from the child's perspective: The Children's Perception of Interparental Conflict Scale. Child Development, 63(3), 558-572. 
Heinrichs, N., Cronrath, A.-L., Degen, M., \& Snyder, D. K. (2010). The link between child emotional and behavioral problems and couple functioning. Family Science, 1, 152172. http://doi.org/10.1080/19424620.2010.569366

Katz, L. F., \& Gottman, J. M. (1993). Patterns of marital conflict predict children's internalizing and externalizing behaviors. Developmental Psychology, 29(6), 940-950.

Kuster, M., Bernecker, K., Backes, S., Brandstätter, V., Nussbeck, F. W., Bradbury, T. N., ... Bodenmann, G. (2015). Avoidance orientation and the escalation of negative communication in intimate relationships. Journal of Personality and Social Psychology, 109(2), 262-275. http://doi.org/10.1037/pspi0000025

Schwarz, B., \& Siffert, A. (2010). Die Bedrohlichkeit elterlicher Konflikte aus Sicht der Kinder. Eine deutsche Fassung der Skala Threat aus der Children's Perception of Interparental Conflict Scale. [Children's perception of threat in interparental conflict: A German version of the Threat Scale from the Children's Perception of Interparental Conflict Scale]. Diagnostica, 56(4), 222-229. http://doi.org/10.1026/0012$1924 / \mathrm{a} 000027$

Shifflett-Simpson, K., \& Cummings, E. M. (1996). Mixed message resolution and children's responses to interadult conflict. Child Development, 67(2), 437-448. http://doi.org/10.1111/1467-8624.ep9605280320

Sturge-Apple, M. L., Davies, P. T., \& Cummings, E. M. (2006). Impact of hostility and withdrawal in interparental conflict on parental emotional unavailability and children's adjustment difficulties. Child Development, 77(6), 1623-1641.

Zemp, M., \& Bodenmann, G. (2014). “Mom and Dad are arguing again”- Parental conflict and its implications for children. Published dissertation. University of Zurich, Switzerland.

Zemp, M., Merrilees, C. E., \& Bodenmann, G. (2014). How much positivity between parents is needed to buffer the impact of parental negativity on child adjustment? Family 
Relations, 63, 602-615. http://doi.org/10.1111/fare.12091 
Table 1

Means, standard deviations, and correlations among study variables

\begin{tabular}{|c|c|c|c|c|c|c|c|c|c|c|}
\hline & 1 & 2 & 3 & 4 & 5 & 6 & 7 & 8 & 9 & Mean $(S D)$ \\
\hline 1. Mothers' nonverbal positivity & - & & & & & & & & & $4.37(4.33)$ \\
\hline 2. Mothers' verbal positivity & $.43 * *$ & - & & & & & & & & $12.93(6.38)$ \\
\hline 3. Fathers' nonverbal positivity & $.42 * *$ & .21 & - & & & & & & & $5.18(5.98)$ \\
\hline 4. Fathers' verbal positivity & $.36^{*}$ & $.37 *$ & .28 & - & & & & & & $14.02(6.59)$ \\
\hline 5. Mothers' nonverbal negativity & -.03 & $.39 *$ & -.04 & .17 & - & & & & & $1.30(2.50)$ \\
\hline 6. Mothers' verbal negativity & -.16 & -.11 & -.17 & -.02 & $.57 * * *$ & - & & - & & $5.63(5.63)$ \\
\hline 7. Fathers' nonverbal negativity & -.21 & -.17 & -.23 & -.11 & $.51 * * *$ & $.68 * * *$ & - & & - & $1.12(2.29)$ \\
\hline 8. Fathers' verbal negativity & -.08 & .07 & -.19 & -.20 & $.40 * *$ & $.76 * * *$ & $.47 * *$ & - & & $3.78(4.80)$ \\
\hline 9. Children's perceived threat & -.17 & $-.32 *$ & -.12 & .05 & -.14 & .18 & $.33 *$ & .02 & - & $2.04(.93)$ \\
\hline 10. Children's insecure family representations & $-.31 *$ & -.24 & -.17 & -.17 & .17 & .21 & $.51 * * *$ & -.06 & $.42 * *$ & $1.53(.63)$ \\
\hline
\end{tabular}

Note. ${ }^{*} p<.05, * * p<0.01, * * * p<.001$. 
Table 2

Mothers' and fathers' verbal and nonverbal positivity and negativity as predictors of

children's perceived threat and insecure family representations

\begin{tabular}{lcccccc}
\hline & \multicolumn{3}{c}{ Perceived threat } & \multicolumn{3}{c}{ Insecure family representations } \\
\cline { 2 - 7 } Predictors & $\beta$ & $\Delta R^{2}$ & $R^{2}$ & $\beta$ & $\Delta R^{2}$ & $R^{2}$ \\
\hline Step 1 & & .09 & .09 & & .13 & .13 \\
Children's age & -.14 & & & $-.28^{*}$ & & \\
Children's gender & .15 & & & .11 & & \\
Step 2 & & $.23^{*}$ & $.32^{*}$ & & $.35^{* * *}$ & $.48^{* * *}$ \\
Mothers' verbal negativity & .09 & & & .12 & & \\
Fathers' verbal negativity & -.05 & & & -.45 & & \\
Mothers' nonverbal negativity & -.38 & & & .04 & & \\
Fathers' nonverbal negativity & $.47^{*}$ & & & $.57^{* *}$ & & $.53^{* *}$ \\
Step 3 & & .03 & .35 & & .05 & \\
Mothers' verbal positivity & -.12 & & & .00 & & \\
Fathers' verbal positivity & .22 & & & -.16 & & \\
Mothers' nonverbal positivity & -.08 & & & -.14 & & \\
Fathers' nonverbal positivity & -.01 & & & .03 & & \\
\hline
\end{tabular}

Note. Standardized regression coefficients $(\beta)$ of the last step are reported. ${ }^{*} p<.05, * * p<0.01, * * * p<.001$. 


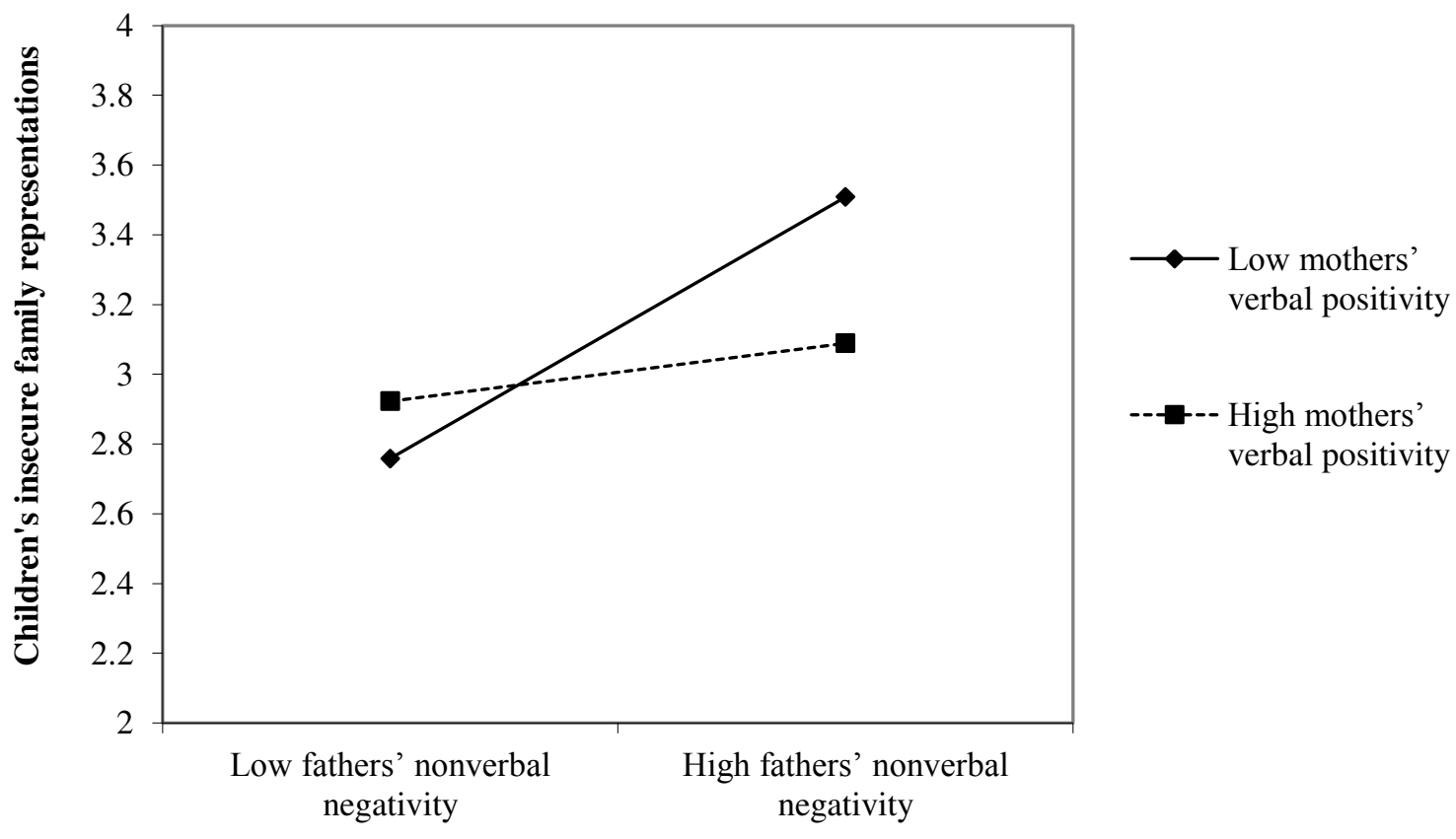

Figure 1. The impact of fathers' nonverbal negativity on children's insecure family representations moderated by mothers' verbal positivity. 